\title{
BLM Deficiency Is Not Associated with Sensitivity to Hydroxyurea-Induced Replication Stress
}

\author{
Kenza Lahkim Bennani-Belhaj, ${ }^{1,2}$ Géraldine Buhagiar-Labarchède, ${ }^{1,2}$ Nada Jmari,, \\ Rosine Onclercq-Delic, ${ }^{1,2}$ and Mounira Amor-Guéret ${ }^{1,2}$ \\ ${ }^{1}$ Institut Curie, Centre de Recherche, Centre Universitaire, Bât. 110, 91405 Orsay, France \\ ${ }^{2}$ CNRS, UMR 3348, 91405 Orsay, France
}

Correspondence should be addressed to Mounira Amor-Guéret, mounira.amor@curie.u-psud.fr

Received 11 May 2010; Accepted 19 July 2010

Academic Editor: Ashis Basu

Copyright (C) 2010 Kenza Lahkim Bennani-Belhaj et al. This is an open access article distributed under the Creative Commons Attribution License, which permits unrestricted use, distribution, and reproduction in any medium, provided the original work is properly cited.

\begin{abstract}
Bloom's syndrome (BS) displays one of the strongest known correlations between chromosomal instability and a high risk of cancer at an early age. BS cells combine a reduced average fork velocity with constitutive endogenous replication stress. However, the response of BS cells to replication stress induced by hydroxyurea (HU), which strongly slows the progression of replication forks, remains unclear due to publication of conflicting results. Using two different cellular models of BS, we showed that BLM deficiency is not associated with sensitivity to HU, in terms of clonogenic survival, DSB generation, and SCE induction. We suggest that surviving BLM-deficient cells are selected on the basis of their ability to deal with an endogenous replication stress induced by replication fork slowing, resulting in insensitivity to $\mathrm{HU}$-induced replication stress.
\end{abstract}

\section{Introduction}

Bloom's syndrome (BS) combines marked genetic instability with an increase in the risk of cancer development and results from mutations in the BLM gene, which encodes BLM, a RecQ 3'-5' DNA helicase [1]. BS cells have very high frequencies of sister chromatid exchanges (SCEs) mediated by RAD51-dependent homologous recombinations [2-4]. Physical and functional links between BLM, replication and HR have been found. BLM deficiency is associated with replication abnormalities [5-9] and with an increase in HR, including a higher frequency of spontaneous symmetric quadriradial interchanges, SCEs, and an increase in the generation of homozygosity [10]. Following replication arrest, BLM coprecipitates with RAD51 [11, 12] and the primary mediators of the S-phase checkpoint, ATR and Chk1 [13]. BLM and RAD51 are colocalized during replication fork stalling and reside in a matrix-bound complex [14, 15]. During replication stress, BLM, 53BP1, and RAD51 form a complex; Chk1-mediated phosphorylation of 53BP1 enhances its binding to BLM and is required for the accumulation of 53BP1 at the site of stalled replication, and BLM enhances the colocalization of 53BP1 and RAD51 during replication arrest [16]. BLM-deficient cells display constitutively large numbers of RAD51-containing foci. Both BLM and 53BP1 abolish the formation of endogenous RAD51 foci and disrupt RAD51 polymerization [11, 16]. SUMOylation of BLM regulates its association with RAD51 by promoting its recruitment and/or retention to damaged replication forks [17]. BLM also acts downstream from RAD51 to rescue anaphase bridges resulting from RAD51 deficiency, probably at difficult-to-replicate DNA sequences such as fragile sites [4]. In vitro, BLM unwinds DNA structures mimicking replication forks and HR intermediates, such as D-loops, and catalyzes the branch migration of Holliday junctions [18-20]. It resolves double Holliday junctions, together with topoisomerase III $\alpha$, Rmi1/BLAP75, and Rmi2 [21, 22], and catalyzes the regression of replication forks [23, 24]. BLM inhibits the D-loop formation catalyzed by RAD51, by displacing RAD51 from single-stranded DNA, thereby disrupting nucleoprotein filaments [25]. Several models of the maintenance of genome integrity by BLM during DNA replication have been developed, most suggesting that BLM restarts replication after the stalling of the fork [26, 27]. In 
the absence of BLM, cells display a slowing of replication fork progression associated with constitutive replication stress [9]. This raises questions about the response of BLMdeficient cells to an exogenous replicative stress slowing the progression of replication still further, such as hydroxyurea (HU). HU inhibits the ribonucleotide reductase commonly used to induce replicational stress which slows fork rate progression with respect to the temporal programme of origin activation [28]. Conflicting data have been reported concerning the sensitivity of BLM-deficient cells to HU. BLM-deficient cells generated from the chicken DT40 Bcell line display normal sensitivity to HU [29] whereas BS lymphoblastoid cells are resistant to HU-induced apoptosis [30], and BS GM08505 fibroblast cells are hypersensitive to HU [31]. In this paper, we used two different cellular models of BS to investigate the sensitivity of BLM-deficient cells to $\mathrm{HU}$-induced replication stress. We show that BLM deficiency is not associated with sensitivity to $\mathrm{HU}$, in terms of clonal growth, DSB generation, and SCE induction. We discuss these results in light of the reported cellular responses of BLM-deficient cells to replication stress.

\section{Materials and Methods}

2.1. Cell Cultures and Transfections. The SV40-transformed BS fibroblast cell line GM08505B and HeLa cells were used as previously described [32]. HeLaV cells and HeLash cells were obtained as described elsewhere [4]. For transient transfection assay siRNAs, $3-4 \times 10^{5}$ cells were used to seed $3 \mathrm{ml}$ of DMEM in six-well plates. Cells were transfected with siRNAs specific for BLM (ON-TARGETplus, SMARTpool, Dharmacon), or negative control siRNAs (ON-TARGETplus siCONTROL Nontargeting Pool, Dharmacon) at a final concentration of $100 \mathrm{nM}$ using DharmaFect $1^{\mathrm{TM}}$ (Dharmacon), according to the manufacturer's instructions.

BS-GFP and BS-GFP-BLM cells were obtained by transfecting BS GM08505B cells with the EGFP-C1 vector alone (Clontech, Mountain View, CA), or with this vector containing the full length BLM cDNA [33], respectively, using JetPEI reagent (Ozyme). After 48 hours, selection with 800 to $1600 \mu \mathrm{g} / \mathrm{ml}$ of $\mathrm{G} 418$ (Invitrogen) was applied. Individual colonies were isolated and maintained in DMEM containing $500 \mu \mathrm{g} / \mathrm{ml} \mathrm{G} 418$.

2.2. Chemicals. Hydroxyurea (HU) (Sigma) was used at a final concentration of $2 \mathrm{mM}$ or $5 \mathrm{mM}$.

2.3. Western Blot Analysis. Cells were lysed in $350 \mathrm{mM}$ $\mathrm{NaCl}, 50 \mathrm{mM}$ Tris-HCl pH 7.5, 1\% NP-40, $1 \mathrm{mM} \mathrm{NaF}$, and protease inhibitors for $30 \mathrm{~min}$ on ice, sonicated and heated. Samples equivalent to 15 or $30 \mu \mathrm{g}$ of protein were subjected to electrophoresis in Novex $4-12 \%$ Bis-Tris precast gels (Invitrogen). The procedures used for gel electrophoresis and immunoblotting were as previously described [34].

2.4. Flow Cytometry Analysis. Cells were fixed with $70 \%$ ethanol at $-20^{\circ} \mathrm{C}$ for at least $30 \mathrm{~min}$. After 2 washes, cells were incubated for $30 \mathrm{~min}$ at $37^{\circ} \mathrm{C}$ in PBS containing
$100 \mu \mathrm{g} / \mathrm{ml}$ RNase A (Sigma) and $10 \mu \mathrm{g} / \mathrm{m} 1$ propidium iodide (Sigma). The DNA content was determined by measuring fluorescent intensities on FACS-calibur flow cytometer (Becton Dickinson). Data were processed with Cell Quest software.

2.5. Antibodies. All the commercial antibodies were used according to the manufacturers' specifications. The primary antibodies used against BLM were ab476 (1:1000; rabbit, Abcam) and C18 (1:150; goat, Santa-Cruz Biotechnology). We used rabbit polyclonal antibodies against Chk1 ser317, Chk2 threonine 68, and H2AX serine 139 (1:1000; Cell Signaling), $\beta$-actin ( $1: 10000$; Sigma), and GAPDH $(1: 5000$; Millipore).

Horseradish peroxidase-conjugated goat antimouse $\operatorname{IgG}$ and goat antirabbit IgG (Santa Cruz Biotechnology) were used as secondary antobodies, at dilutions of 1:5000 and $1: 10000$.

2.6. Sister Chromatid Exchange Assays. Cells were left untreated or were transfected as indicated. After $24 \mathrm{~h}$ of transfection with siRNA, cells were left untreated or were treated with $\mathrm{HU}$, transferred to slides and cultured in the presence of $10 \mathrm{mM} 5$-bromodeoxyuridine (Sigma) at $37^{\circ} \mathrm{C}$, under an atmosphere containing $5 \% \mathrm{CO}_{2}$. After $40 \mathrm{~h}(\mathrm{HeLaV}$ and HeLashBLM cells) or $50 \mathrm{~h}$ (BS-GFP or BS-GFP-BLM) of incubation, colchicine (Sigma) was added to a final concentration of $0.1 \mathrm{mg} / \mathrm{ml}$, and the cells were incubated for 1 hour. They were then incubated in hypotonic solution $(1: 6$ (vol/vol) FCS-distilled water) and fixed by incubation with a $3: 1$ ( vol/vol) mixture of methanol and acetic acid. Cells were then stained by incubation with $10 \mathrm{mg} / \mathrm{ml}$ Hoechst 33258 (Sigma) in distilled water for 20 minutes, rinsed with $2 \times$ SSC (Euromedex), exposed to UV light at $365 \mathrm{~nm}$ and at a distance of $10 \mathrm{~cm}$ for 105 minutes, rinsed in distilled water, stained by incubation with $2 \%$ Giemsa solution (VWR) for 16 minutes, rinsed in distilled water, dried, and mounted. Chromosomes were observed with a Leica DMRB microscope at 100x magnification. Metaphases were captured with a SONY DXC 930 P camera, and SCEs were analyzed.

2.7. Clonogenic Survival Assays. Untreated or HU-treated cells were plated in drug-free medium at 3 densities, in triplicate, for the counting of 30 to 300 clones depending on expected survival. Alternatively, cells were plated and treated as previously described [31]. After 14 to 21 days of incubation colonies were fixed and stained with methylene blue $(5 \mathrm{~g} / \mathrm{l}$ in $50 \%$ water and 50\% methanol) and scored. Only experiments giving a linear correlation between the different dilutions were considered. Cell survival was estimated by dividing the number of colony-forming units in treated samples by the number of colony-forming units in untreated samples, with control cell survival defined as 1 . The percentage of cell survival is indicated within each histogram.

2.8. Comet Assays. BS-GFP and BS-GFP-BLM cells or HeLashBLM and HeLaV transfected as in Figure 1(a) were left untreated or were treated with $2 \mathrm{mM} \mathrm{HU}$ for $16 \mathrm{~h}$ or $48 \mathrm{~h}$. 

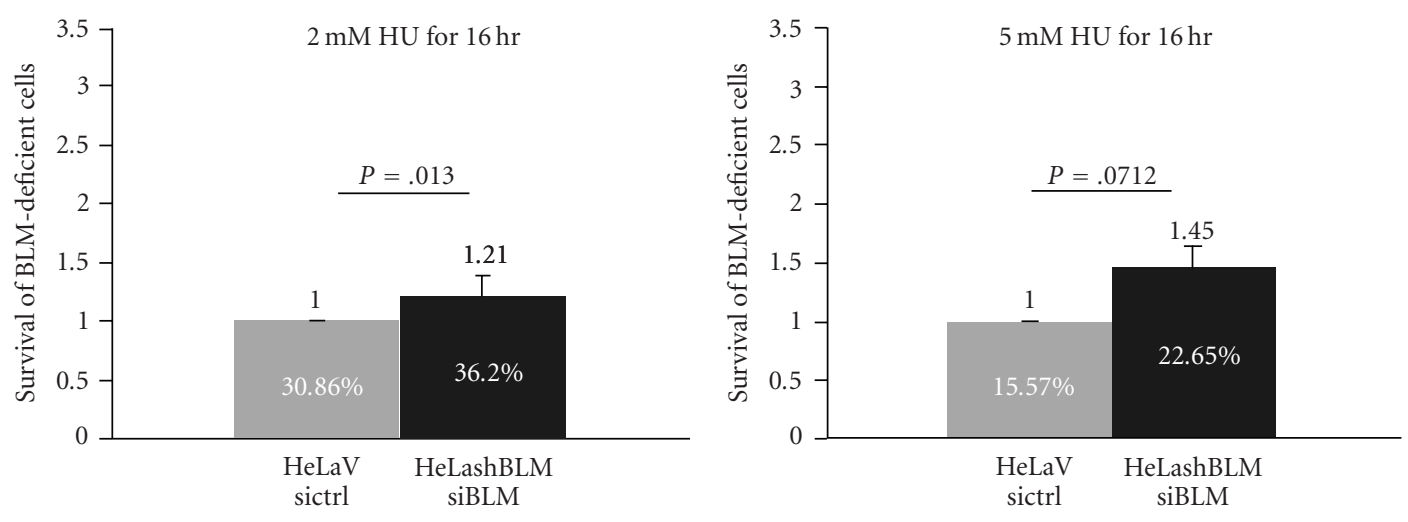

(a)

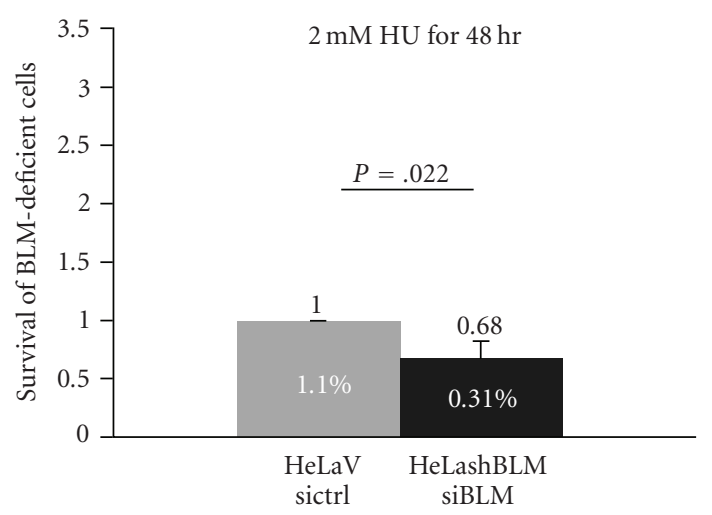

(b)

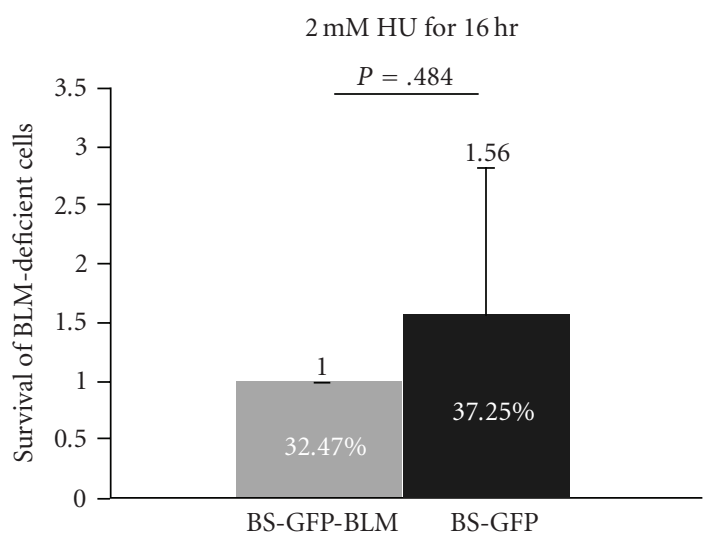

(c)

Figure 1: BLM-downregulated HeLa cells and BS cells are insensitive to HU-induced replication stress. (a) HeLaV and HeLashBLM cells were transfected with $100 \mathrm{nM}$ of a negative control siRNA (ctrl) or with $100 \mathrm{nM}$ of siRNA targeting the BLM mRNA (BLM), respectively. After $24 \mathrm{~h}$, cells were left untreated or were treated with $2 \mathrm{mM}$ or $5 \mathrm{mM}$ HU for $16 \mathrm{~h}$. Cells were then plated in triplicate at three densities in drug-free medium. The means of six independent experiments for $2 \mathrm{mM} \mathrm{HU}$ and of two independent experiments for $5 \mathrm{mM} H \mathrm{HU}$ are shown. The error bars indicate SD. (b) As in (a) except that cells were treated with $2 \mathrm{mM} \mathrm{HU}$ for $48 \mathrm{hr}$, the means of 3 independent experiments are shown. (c) BS-GFP and BS-GFP-BLM cell lines were left untreated or were treated with $2 \mathrm{mM}$ HU for $16 \mathrm{~h}$ and plated as in (a). The means of 3 independent experiments are shown.

After $24 \mathrm{~h}$, cells were left untreated or were treated with $2 \mathrm{mM}$ $\mathrm{HU}$ for $16 \mathrm{~h}$ or $48 \mathrm{~h}$. At the end of the treatment period, the cells were treated with Accutase (PAA). Aliquots of cell suspension were mixed with an equal volume of $1 \%$ lowmelting-point agarose in DMEM to obtain a suspension of cells in $0.5 \%$ agarose, which was then dispensed onto microscope slides (with frosted ends) coated with a layer of $0.5 \%$ normal-melting-point agarose. Slides were incubated in lysis solution $[2.5 \mathrm{~mol} / \mathrm{L} \mathrm{NaCl}, 100 \mathrm{mmol} / \mathrm{L}$ EDTA, $10 \mathrm{mmol} / \mathrm{L}$ Tris, $1 \%$ sodium lauryl sarcosinate, $10 \%$ DMSO, and $1 \%$ TritonX-100 ( $\mathrm{pH} \mathrm{10)]} \mathrm{at} 4{ }^{\circ} \mathrm{C}$ for $1 \mathrm{~h}$, then denaturated in alkali buffer $(0.3 \mathrm{~mol} / \mathrm{L} \mathrm{NaOH}, \mathrm{pH} 13$ and $1 \mathrm{mmol} / \mathrm{L}$ EDTA) for 40 minutes at $20^{\circ} \mathrm{C}$ and subjected to electrophoresis for $25 \mathrm{~min}$ at $25 \mathrm{~V}(300 \mathrm{~mA})$. Slides were immersed in neutralization buffer $(400 \mathrm{mmol} / \mathrm{L}$ Tris- $\mathrm{HCl}, \mathrm{pH}$ 7.5) for at least 5 minutes. They were then drained, rinsed carefully with distilled water, and stained with ethidium bromide staining solution $(20 \mu \mathrm{g} / \mathrm{ml})$ before being covered with a coverslip. For the visualization of DNA damage, ethidium bromide- stained DNA was observed at a magnification of $x 20$, under a fluorescence microscope. Between 100 and 110 cells per sample and per experiment were analyzed in Comet Assay 2 software (Perceptive Instrument).

2.9. Statistical Methods. Significance was assessed with Student's $t$-test. For all tests, $P<.05$ was considered statistically significant.

\section{Results}

3.1. Both HeLa Cells with BLM Downregulation and BS Cells Are Insensitive to HU-Induced Replication Stress. We investigated whether BLM downregulation was associated with changes in the sensitivity of cells to HU-induced replication stress. We first used a new cellular model for BS consisting of HeLa cells constitutively expressing an shRNA specific for BLM and transiently transfected with a pool of siRNAs directed against sequences other than that targeted 
by shBLM (HeLash-siBLM), together with the corresponding control cells (HeLaV-sictrl) [4]. We assessed HeLash-siBLM sensitivity to HU in clonogenic survival assays. BLM mRNA levels and SCE frequency were assessed in all experiments with HeLash-siBLM (data not shown). After treatment with 2 or $5 \mathrm{mM}$ HU for $16 \mathrm{hr}$, HeLash-siBLM cells were either less sensitive or displayed similar levels of sensitivity to HU than control cells, respectively (Figure 1(a)). As BS cell hypersensitivity was reported after $48 \mathrm{~h}$ of exposure to HU concentrations from 0.01 to $10 \mathrm{mM}$ in a previous study [31], we repeated the experiments after $48 \mathrm{~h}$ of exposure to $2 \mathrm{mM}$ HU. The clonogenic survival of both HeLa cells with BLM downregulation and control cells was strongly decreased, with BLM-downregulated cells significantly more sensitive to $48 \mathrm{~h}$ of exposure to HU than control cells (Figure 1(b)). These experiments were repeated with BS GM08505 fibroblasts (BS-GFP) and their complemented counterparts (BS-GFP-BLM) (see Section 2). The clonogenic survival of BS cells and control cells was similar after $16 \mathrm{~h}$ of exposure to HU (Figure 1(c)). After $48 \mathrm{~h}$ of exposure to $\mathrm{HU}$, we detected no clones, for either BS cells or BLMcomplemented cells. Increasing the number of cells plated by a factor 10 and using two different protocols did not affect the results obtained. This indicates that the BS cell line we used behaves differently from the one used by Davies et al. [31], potentially because one of them derived in culture due to the mutator and hyper-rec phenotype of BS cells [1]. Altogether our results indicate that in terms of clonal survival, BLM deficiency is not associated with an increase in the sensitivity to $16 \mathrm{~h}$ of treatment with HU. However, BLM-downregulated $\mathrm{HeLa}$ cells are significantly more sensitive to $48 \mathrm{~h}$ of $\mathrm{HU}$ treatment than control cells are.

\subsection{Levels of HU-Induced DSBs Are Similar in BLM-Deficient} Cells and in Control Cells. The prolonged treatment of cells with HU results in the accumulation of DSBs [35]. We carried out a time-course study of the effect of $\mathrm{HU}$ on DSB levels in BLM-downregulated HeLa cells and in control cells. DSB induction was assessed by evaluating levels of histone H2AX phosphorylated at serine 139 ( $\gamma$-H2AX) and of checkpoint kinase 2 phosphorylated at threonine 68 (Chk2 pT68). Chk1 activation and BLM accumulation were induced by blocking replication $[34,36]$. We therefore determined the levels of activated Chk1 phosphorylated at serine 345 (Chk1 pS345) and BLM. The progressive accumulation of BLM in control cells was observed, with the highest levels after 16 to $24 \mathrm{~h}$ of exposure to $\mathrm{HU}$ (Figure 2(a)). No BLM was detected in HeLash-siBLM cells, as expected. The efficiency of replication blockade by $\mathrm{HU}$ was confirmed by FACS analysis and by the detection of activated Chk1 in both control cells and BLM-depleted HeLa cells. Significantly higher levels of accumulation of $\gamma$-H2AX and activated Chk2 were observed in control cells and in BLM-downregulated HeLa cells after $48 \mathrm{~h}$ of HU exposure than after $16 \mathrm{~h}$ (Figure 2(a)). The amounts of $\gamma$-H2AX and of Chk2pT68 detected in response to HU treatment were similar in BLM-deficient cells and in control cells. In BSGFP cells and their complemented counterparts, $\gamma$-H2AX accumulation was also stronger after $48 \mathrm{~h}$ of HU treatment than after $16 \mathrm{~h}$ (Figure 2(b)).

We evaluated HU genotoxicity in BLM-deficient cells further, by carrying out an in vitro alkaline DNA comet assay [37]. The mean tail moment (a numerical measurement of the DNA damage defined as the product of the tail length and the fraction of total DNA in the tail) was similar in BLM-deficient cells (HeLash-siBLM or BSGFP) and in control cells (HeLaV-sictrl or BS-GFP-BLM, respectively), whether untreated or treated with $2 \mathrm{mM} \mathrm{HU}$ for $16 \mathrm{~h}$ (Figures 2(c), 2(d), and 2(e)). However, the mean tail moment was significantly higher after $48 \mathrm{~h}$ of $\mathrm{HU}$ treatment than in the absence of treatment or after $16 \mathrm{~h}$ of treatment, by a factor of about two in both BS cells and their complemented counterparts (Figure 2(e)), and by factors of four to ten in BLM-downregulated HeLa cells and their controls (Figure $2(\mathrm{~d})$ ). Thus, $16 \mathrm{~h}$ of treatment with $2 \mathrm{mM} \mathrm{HU}$ activates the Chk1-mediated replication checkpoint but does not generate a significant increase in DNA damage whereas $48 \mathrm{~h}$ of treatment with $2 \mathrm{mM} \mathrm{HU}$ leads to a significant increase in DNA damage, to similar levels in BLM-deficient cells control cells. BLM deficiency is not therefore associated with an increase in DSB induction in response to $\mathrm{HU}$.

3.3. HU Treatment Induces a Similar Increase in the Frequency of SCEs in BLM-Deficient Cells and Control Cells. $\mathrm{HU}$ treatment efficiently induces SCEs formation [38]. We analyzed the effect of HU-induced replication stress on SCEs levels in BLM-deficient cells and in control cells. We found a slight but significant increase in SCE levels in both BLMdownregulated HeLa cells (x1.4) and in BS cells (x1.3) this increase is similar to that observed in the corresponding control cells (x1.7 and x1.4, resp.) (Figures 3(a) and 3(b)). Thus, BLM deficiency is not associated with an increase in SCEs induction in response to HU.

\section{Discussion}

We used hydroxyurea to investigate the cellular consequences of HU-induced replication stress in two cellular models of BS. We found that although BLM-deficient cells have a strong increase in SCE frequency due to BLM deficiency, the further increase in the SCE frequency induced by the treatment with HU was similar to that of control cells. Thus, BLM deficiency is not associated with sensitivity to HU in terms of SCE induction. We also showed that BLM-deficient cells were insensitive to $\mathrm{HU}$ induced replication stress $(2$ or $5 \mathrm{mM}$ $\mathrm{HU}$ for $16 \mathrm{~h}$ ), consistent with the normal sensitivity to $\mathrm{HU}$ of the BLM-defective chicken DT40 cells [29]. By contrast, Davies et al. [31] showed that BS cells were hypersensitive to prolonged exposure to HU. We also found that BLMdownregulated HeLa cells were significantly more sensitive to treatment with $\mathrm{HU}$ for $48 \mathrm{~h}$ than control cells were. We investigated the reasons for this sensitivity of BLM-deficient cells to $48 \mathrm{~h}$ of HU treatment but not to $16 \mathrm{~h}$ of treatment, by analyzing the effects of HU on DSB induction. We found that $48 \mathrm{~h}$ of HU treatment generated numerous DSBs whereas 

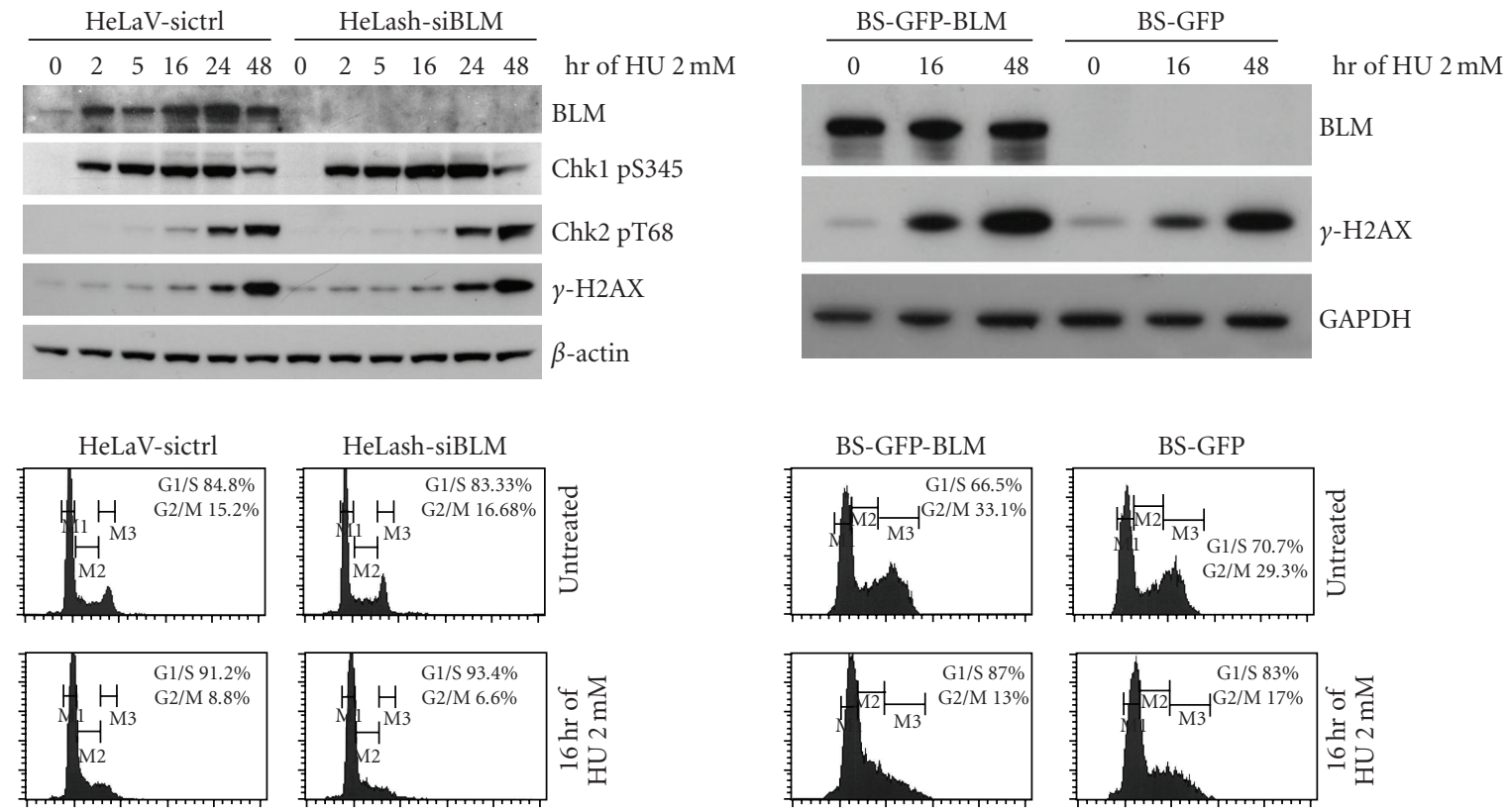

(a)
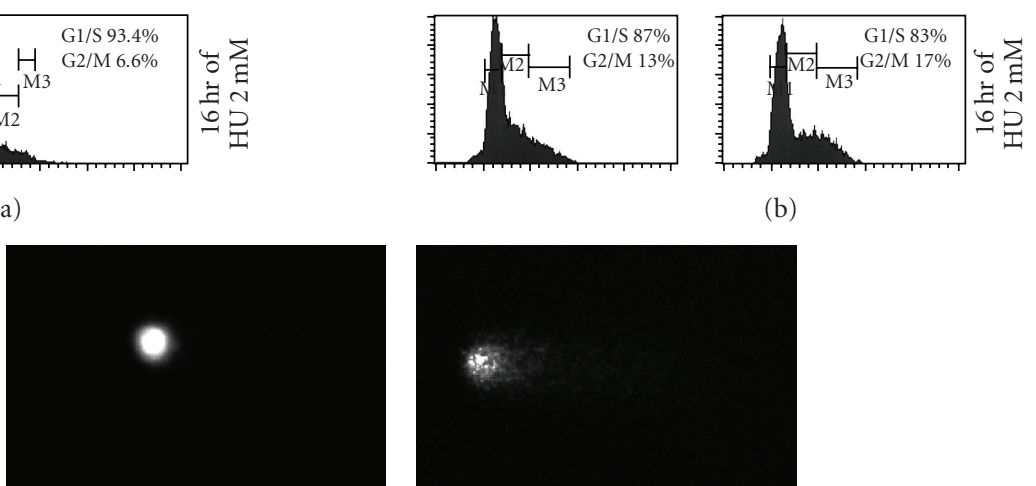

(c)

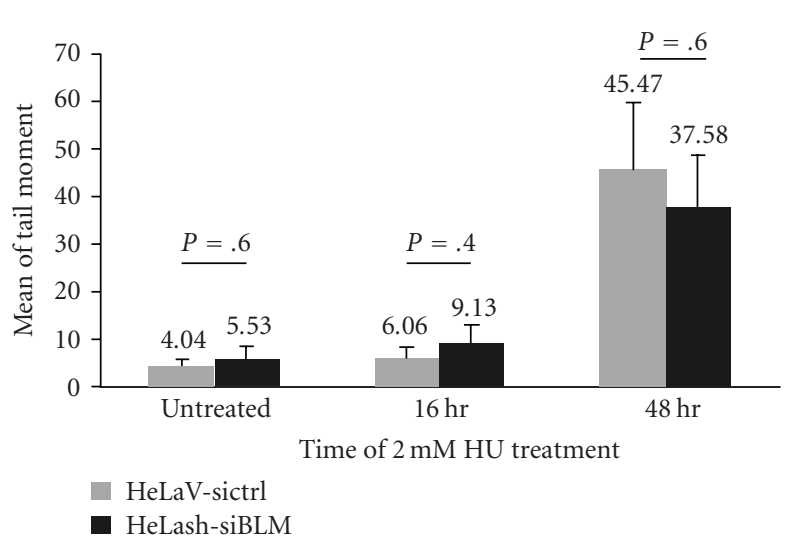

(d)

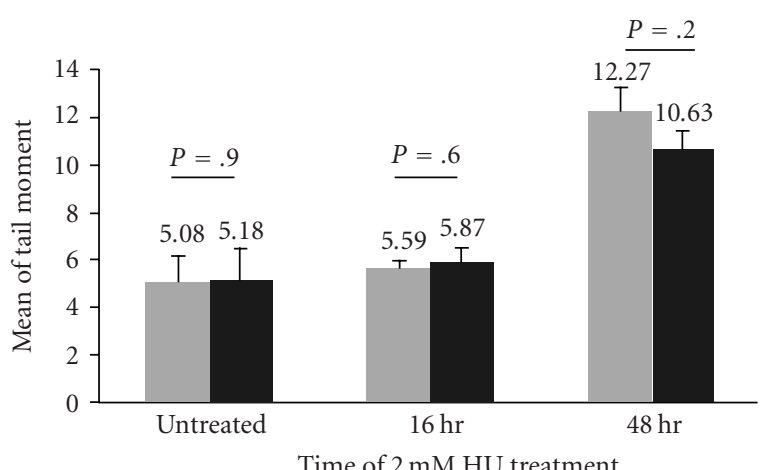

BS-GFP-BLM

BS-GFP

FIGURE 2: Levels of HU-induced DSBs are similar in BLM-deficient cells and control cells. (a) HeLaV and HeLashBLM cells were transfected as in Figure 1(a). Upper panel: After $24 \mathrm{~h}$, cells were left untreated (0) or were treated with $2 \mathrm{mM}$ HU for the indicated times. Protein extracts were subjected to SDS-PAGE. The membrane was probed with anti-BLM (C18), anti-Chk1 pS345, anti-Chk2 pT68, and anti- $\gamma$ $\mathrm{H} 2 \mathrm{AX}$ antibodies, and with anti- $\beta$-actin antibody, as a loading control. The membrane was stripped and reblocked between successive antibody incubations. Lower panel: After $24 \mathrm{~h}$, cells left untreated or treated with $2 \mathrm{mM} \mathrm{HU}$ for $16 \mathrm{~h}$ were harvested, fixed, and analyzed by FACS. (b) BS-GFP and BS-GFP-BLM cells were left untreated or were treated with $2 \mathrm{mM} \mathrm{HU}$ for the indicated times. Protein extracts were subjected to SDS-PAGE and the bands were transferred to a membrane. The membrane was probed with anti-BLM (C18), anti- $\gamma$-H2AX antibodies, and with anti-GAPDH antibody, as a loading control. Lower panel: After $24 \mathrm{~h}$, cells left untreated or treated with $2 \mathrm{mM}$ HU for $16 \mathrm{~h}$ were harvested, fixed, and analyzed by FACS. (c) Representative images of HeLa cells in the comet assays. (Left) Untreated cell. (Right) Example of cell displaying an increase in DNA migration after $48 \mathrm{~h}$ of HU treatment, due to DNA breaks. (d) The effect of $2 \mathrm{mM}$ $\mathrm{HU}$ treatment on DNA migration (tail moment) in the comet assays with HeLaV and HeLash BLM cells transfected as in Figure 1(a). After $24 \mathrm{~h}$ of transfection, cells were left untreated or were treated with $2 \mathrm{mM} \mathrm{HU}$ for $16 \mathrm{~h}$ or $48 \mathrm{~h}$. The cells were subjected to comet assays (see Section 2). Two independent experiments were analyzed for each set of conditions. Between 100, and 110 cells were scored for each set of conditions, in each experiment. Error bars represent standard errors of the mean. (e) As in (d), using BS-GFP-BLM or BS-GFP cells left untreated or treated with $2 \mathrm{mM} \mathrm{HU}$ for $16 \mathrm{~h}$ or $48 \mathrm{~h}$. 


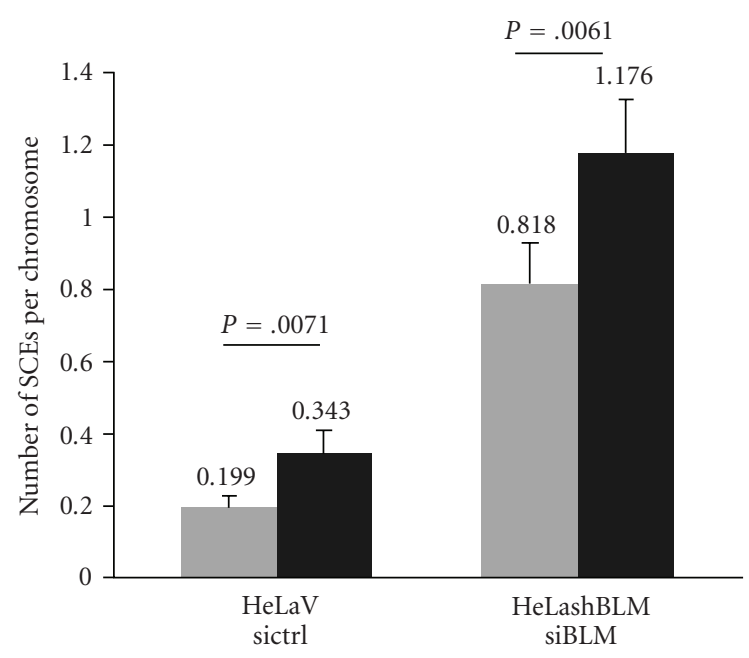

(a)

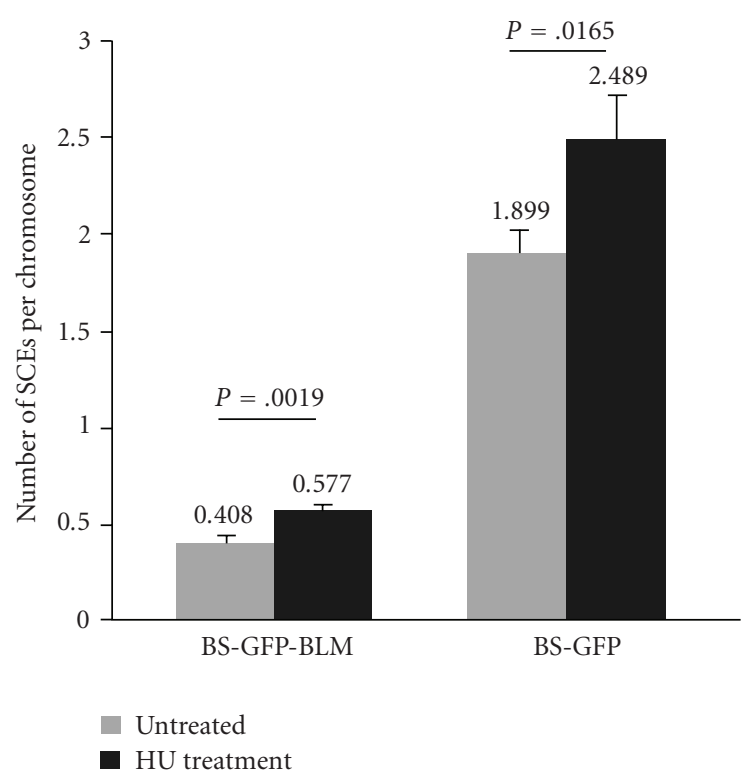

(b)

FIGURE 3: Levels of HU-induced SCEs are similar in BLM-deficient cells and control cells. (a) Number of SCEs per chromosome in HeLaV or in HeLashBLM cells transfected as in Figure 1(a), left untreated or treated with $2 \mathrm{mM} \mathrm{HU}$ for $16 \mathrm{~h}$. Between 2174 and 4314 chromosomes from 5 independent experiments were analyzed for each set of conditions. Errors bars represent standard errors of the means. (b) Number of SCEs per chromosome in BS-GFPBLM and BS-GFP cells left untreated or treated as in (a). Between 1864 and 2255 chromosomes from 4 independent experiments were analyzed for each set of conditions. Errors bars represent standard errors of the means.

$16 \mathrm{~h}$ of treatment did not, as expected [35]. However, the DSB levels determined on the basis of $\gamma$-H2AX detection or in comet assays were found to be similar in BLM-deficient cells and in control cells treated with HU, indicating a lack of association between BLM deficiency and an increase in DSB induction by HU. These results are consistent with the data reported by Rao et al. [39] showing that despite the delay in H2AX phosphorylation on serine 139 observed in BLMdeficient cells treated with $\mathrm{HU}(1 \mathrm{mM})$ or camptothecin $(1 \mu \mathrm{M})$, the number of $\gamma$-H2AX foci per nucleus reaches that of control cells $6 \mathrm{~h}$ after either of these treatments. Camptothecin induces replication-associated DSBs [40], and BS cells are hypersensitive to camptothecin [39]. These results indicate that the reported differences in the sensitivity of BLM-deficient cells to $\mathrm{HU}$ reflect differences in their sensitivity to HU-induced DSBs; this sensitivity depends on the numbers of DSBs generated by the HU treatment, but not on HU-induced replication stress per se that is associated with few DNA breaks. Indeed, unstressed BLM-deficient cells have DNA replication defects, resulting in spontaneously arrested replication forks and a decrease in the distance between origins $[8,9]$. Such inhibition of the progress of replication forks may render BS cells susceptible to some DNA breaks, accounting for constitutive endogenous ATM-Chk2- $\gamma \mathrm{H} 2 \mathrm{AX}$ checkpoint activation detected only by immunofluorescence [9]. Such checkpoint activation has been found in clinical specimens from human tumours at various stages and in cultured cells subjected to replication stress $[41,42]$. Endogenous ATM-Chk2- $\gamma \mathrm{H} 2 \mathrm{AX}$ activation in BS cells is thus thought to reflect a precancerous state, with replication stress associated with few DNA breaks [9]. If BS cells were hypersensitive to such replication stress, they would not survive this constitutive replication defect. We therefore suggest that surviving BLM-deficient cells have been selected on the basis of their ability to survive in the presence of a constitutive replication stress associated with few DNA breaks.

\section{Conclusion}

We showed that the clonogenic survival of BLM-deficient cells was insensitive to hydroxyurea (HU)-induced replication stress. Gamma-H2AX detection and comet assays revealed the numbers of DNA double-strand breaks (DSB) generated by HU treatment to be similar in BLM-deficient cells and control cells. Moreover, BLM deficiency did not further increase the frequency of HU-induced sister chromatid exchanges (SCEs). We propose that BLM-deficient cells are selected to survive with an endogenous replication stress induced by replication fork slowing, resulting in insensitivity to $\mathrm{HU}$-induced replication stress.

\section{Acknowledgments}

The authors thank Nathan Ellis for providing them with the BLM-GFP construct. They also thank Dr. Marie Dutreix (Institut Curie) for advices and helpful discussions and Christophe Roulin (Institut Curie) for expert assistance with comet assays. This paper was supported by Grants from the Institut Curie (PIC), the CNRS, the INCa (PL333), the Cancéropôle/Région Ile-de-France, and the $\mathrm{ARC}$, and by a fellowship from the Cancéropôle/Région Ile-de-France, Association pour la Recherche sur le Cancer, and Ligue Nationale contre le Cancer (Comité de l'Essonne) (K. L. B-B). 


\section{References}

[1] N. A. Ellis, J. Groden, T.-Z. Ye et al., “The Bloom's syndrome gene product is homologous to RecQ helicases," Cell, vol. 83, no. 4, pp. 655-666, 1995.

[2] M. Otsuki, M. Seki, E. Inoue et al., "Functional interactions between BLM and XRCC3 in the cell," Journal of Cell Biology, vol. 179, no. 1, pp. 53-63, 2007.

[3] E. Sonoda, M. S. Sasaki, C. Morrison, Y. Yamaguchi-Iwai, M. Takata, and S. Takeda, "Sister chromatid exchanges are mediated by homologous recombination in vertebrate cells," Molecular and Cellular Biology, vol. 19, no. 7, pp. 5166-5169, 1999.

[4] K. L. Bennani-Belhaj, S. Rouzeau, G. Buhagiar-Labarchède et al., "The Bloom syndrome protein limits the lethality associated with RAD51 deficiency," Molecular Cancer Research, vol. 8, no. 3, pp. 385-394, 2010.

[5] R. Hand and J. German, "A retarded rate of DNA chain growth in Bloom's syndrome," Proceedings of the National Academy of Sciences of the United States of America, vol. 72, no. 2, pp. 758$762,1975$.

[6] F. Giannelli, P. F. Benson, S. A. Pawsey, and P. E. Polani, "Ultraviolet light sensitivity and delayed DNA chain maturation in Bloom's syndrome fibroblasts," Nature, vol. 265, no. 5593, pp. 466-469, 1977.

[7] U. Lonn, S. Lonn, U. Nylen, G. Winblad, and J. German, "An abnormal profile of DNA replication intermediates in Bloom's syndrome," Cancer Research, vol. 50, no. 11, pp. 3141-3145, 1990.

[8] S. L. Davies, P. S. North, and I. D. Hickson, "Role for BLM in replication-fork restart and suppression of origin firing after replicative stress," Nature Structural and Molecular Biology, vol. 14, no. 7, pp. 677-679, 2007.

[9] V. A. Rao, C. Conti, J. Guirouilh-Barbat et al., "Endogenous $\gamma$-H2AX-ATM-Chk2 checkpoint activation in Bloom's syndrome helicase-deficient cells is related to DNA replication arrested forks," Molecular Cancer Research, vol. 5, no. 7, pp. 713-724, 2007.

[10] J. German, "Bloom's syndrome,” Dermatologic Clinics, vol. 13, no. 1, pp. 7-18, 1995.

[11] L. Wu, S. L. Davies, N. C. Levitt, and I. D. Hickson, "Potential role for the BLM helicase in recombinational repair via a conserved interaction with RAD51," The Journal of Biological Chemistry, vol. 276, no. 22, pp. 19375-19381, 2001.

[12] V. Tripathi, T. Nagarjuna, and S. Sengupta, "BLM helicasedependent and -independent roles of 53BP1 during replication stress-mediated homologous recombination," Journal of Cell Biology, vol. 178, no. 1, pp. 9-14, 2007.

[13] S. Sengupta, A. I. Robles, S. P. Linke et al., "Functional interaction between BLM helicase and 53BP1 in a Chk1mediated pathway during S-phase arrest," Journal of Cell Biology, vol. 166, no. 6, pp. 801-813, 2004.

[14] O. Bischof, S.-H. Kim, J. Irving, S. Beresten, N. A. Ellis, and J. Campisi, "Regulation and localization of the Bloom syndrome protein in response to DNA damage," Journal of Cell Biology, vol. 153, no. 2, pp. 367-380, 2001.

[15] S. Sengupta, S. P. Linke, R. Pedeux et al., "BLM helicasedependent transport of $\mathrm{p} 53$ to sites of stalled DNA replication forks modulates homologous recombination," EMBO Journal, vol. 22, no. 5, pp. 1210-1222, 2003.

[16] V. Tripathi, S. Kaur, and S. Sengupta, "Phosphorylationdependent interactions of BLM and 53BP1 are required for their anti-recombinogenic roles during homologous recombination," Carcinogenesis, vol. 29, no. 1, pp. 52-61, 2008.
[17] K. J. Ouyang, L. L. Woo, J. Zhu, D. Huo, M. J. Matunis, and N. A. Ellis, "SUMO modification regulates BLM and RAD51 interaction at damaged replication forks," PLoS Biology, vol. 7, no. 12, Article ID e1000252, 2009.

[18] J. K. Karow, A. Constantinou, J.-L. Li, S. C. West, and I. D. Hickson, "The Bloom's syndrome gene product promotes branch migration of Holliday junctions," Proceedings of the National Academy of Sciences of the United States of America, vol. 97, no. 12, pp. 6504-6508, 2000.

[19] A. J. van Brabant, T. Ye, M. Sanz, J. L. German III, N. A. Ellis, and W. K. Holloman, "Binding and melting of D-loops by the Bloom syndrome helicase," Biochemistry, vol. 39, no. 47, pp. 14617-14625, 2000.

[20] C. Z. Bachrati, R. H. Borts, and I. D. Hickson, "Mobile D-loops are a preferred substrate for the Bloom's syndrome helicase," Nucleic Acids Research, vol. 34, no. 8, pp. 2269-2279, 2006.

[21] S. Raynard, W. Bussen, and P. Sung, "A double holliday junction dissolvasome comprising BLM, topoisomerase III $\alpha$, and BLAP75," The Journal of Biological Chemistry, vol. 281, no. 20, pp. 13861-13864, 2006.

[22] L. Wu, C. Z. Bachrati, J. Ou et al., "BLAP75/RMI1 promotes the BLM-dependent dissolution of homologous recombination intermediates," Proceedings of the National Academy of Sciences of the United States of America, vol. 103, no. 11, pp. 4068-4073, 2006.

[23] A. Machwe, L. Xiao, J. Groden, and D. K. Orren, "The Werner and Bloom syndrome proteins catalyze regression of a model replication fork," Biochemistry, vol. 45, no. 47, pp. 13939 13946, 2006.

[24] C. Ralf, I. D. Hickson, and L. Wu, “The Bloom's syndrome helicase can promote the regression of a model replication fork," The Journal of Biological Chemistry, vol. 281, no. 32, pp. 22839-22846, 2006.

[25] D. V. Bugreev, X. Yu, E. H. Egelman, and A. V. Mazin, "Novel pro- and anti-recombination activities of the Bloom's syndrome helicase," Genes and Development, vol. 21, no. 23, pp. 3085-3094, 2007.

[26] M. Amor-Guéret, "Bloom syndrome, genomic instability and cancer: the SOS-like hypothesis," Cancer Letters, vol. 236, no. 1, pp. 1-12, 2006.

[27] L. Wu, "Role of the BLM helicase in replication fork management," DNA Repair, vol. 6, no. 7, pp. 936-944, 2007.

[28] G. M. Alvino, D. Collingwood, J. M. Murphy, J. Delrow, B. J. Brewer, and M. K. Raghuraman, "Replication in hydroxyurea: it's a matter of time," Molecular and Cellular Biology, vol. 27, no. 18, pp. 6396-6406, 2007.

[29] O. Imamura, K. Fujita, A. Shimamoto et al., "Bloom helicase is involved in DNA surveillance in early s phase in vertebrate cells," Oncogene, vol. 20, no. 10, pp. 1143-1151, 2001.

[30] M. Ababou, V. Dumaire, Y. Lécluse, and M. Amor-Guéret, "Cleavage of BLM and sensitivity of Bloom's syndrome cells to hydroxurea and UV-C radiation," Cell Cycle, vol. 1, no. 4, pp. 262-266, 2002.

[31] S. L. Davies, P. S. North, A. Dart, N. D. Lakin, and I. D. Hickson, "Phosphorylation of the Bloom's syndrome helicase and its role in recovery from S-phase arrest," Molecular and Cellular Biology, vol. 24, no. 3, pp. 1279-1291, 2004.

[32] S. Dutertre, M. Ababou, R. Onclercq et al., "Cell cycle regulation of the endogenous wild type Bloom's syndrome DNA helicase," Oncogene, vol. 19, no. 23, pp. 2731-2738, 2000.

[33] S. Eladad, T.-Z. Ye, P. Hu et al., "Intra-nuclear trafficking of the BLM helicase to DNA damage-induced foci is regulated by SUMO modification," Human Molecular Genetics, vol. 14, no. 10, pp. 1351-1365, 2005. 
[34] M. Ababou, V. Dumaire, Y. Lécluse, and M. Amor-Guéret, "Bloom's syndrome protein response to ultraviolet-C radiation and hydroxyurea-mediated DNA synthesis inhibition," Oncogene, vol. 21, no. 13, pp. 2079-2088, 2002.

[35] Y. Saintigny, F. Delacôte, G. Varès et al., "Characterization of homologous recombination induced by replication inhibition in mammalian cells," EMBO Journal, vol. 20, no. 14, pp. 3861$3870,2001$.

[36] H. Zhao and H. Piwnica-Worms, "ATR-mediated checkpoint pathways regulate phosphorylation and activation of human Chk1," Molecular and Cellular Biology, vol. 21, no. 13, pp. 4129-4139, 2001.

[37] G. Speit and P. Schütz, "The effect of inhibited replication on DNA migration in the comet assay in relation to cytotoxicity and clastogenicity," Mutation Research, vol. 655, no. 1-2, pp. 22-27, 2008.

[38] A. Matsuoka, C. Lundin, F. Johansson et al., "Correlation of sister chromatid exchange formation through homologous recombination with ribonucleotide reductase inhibition," Mutation Research, vol. 547, no. 1-2, pp. 101-107, 2004.

[39] V. A. Rao, A. M. Fan, L. Meng et al., "Phosphorylation of BLM, dissociation from topoisomerase III $\alpha$, and colocalization with $\gamma$-H2AX after topoisomerase I-induced replication damage," Molecular and Cellular Biology, vol. 25, no. 20, pp. 8925-8937, 2005.

[40] Y.-H. Hsiang, M. G. Lihou, and L. F. Liu, "Arrest of replication forks by drug-stabilized topoisomerase I-DNA cleavable complexes as a mechanism of cell killing by camptothecin," Cancer Research, vol. 49, no. 18, pp. 5077-5082, 1989.

[41] J. Bartkova, Z. Hořejší, K. Koed et al., "DNA damage response as a candidate anti-cancer barrier in early human tumorigenesis," Nature, vol. 434, no. 7035, pp. 864-870, 2005.

[42] V. G. Gorgoulis, L.-V. F. Vassiliou, P. Karakaidos et al., "Activation of the DNA damage checkpoint and genomic instability in human precancerous lesions," Nature, vol. 434, no. 7035, pp. 907-913, 2005. 

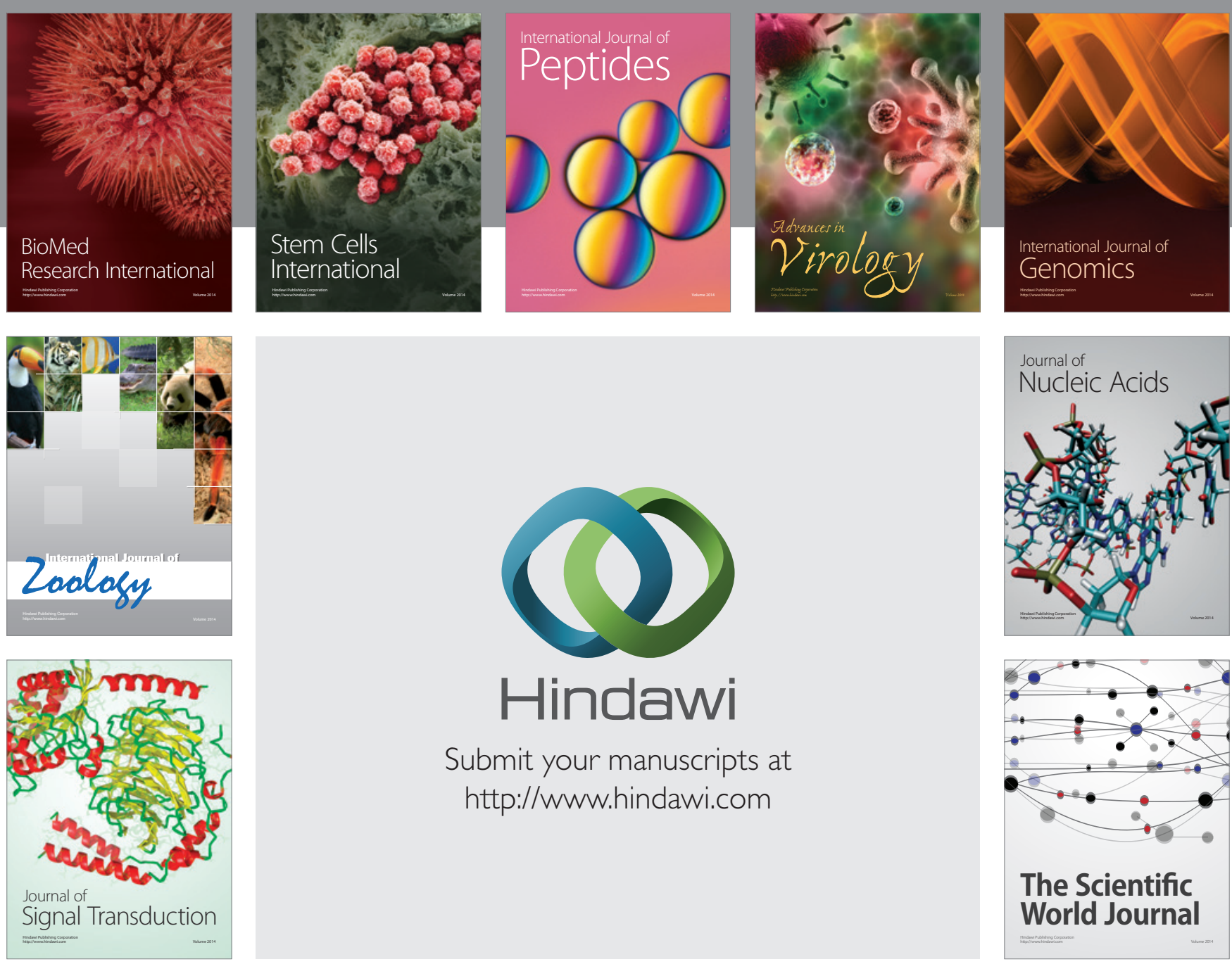

Submit your manuscripts at

http://www.hindawi.com
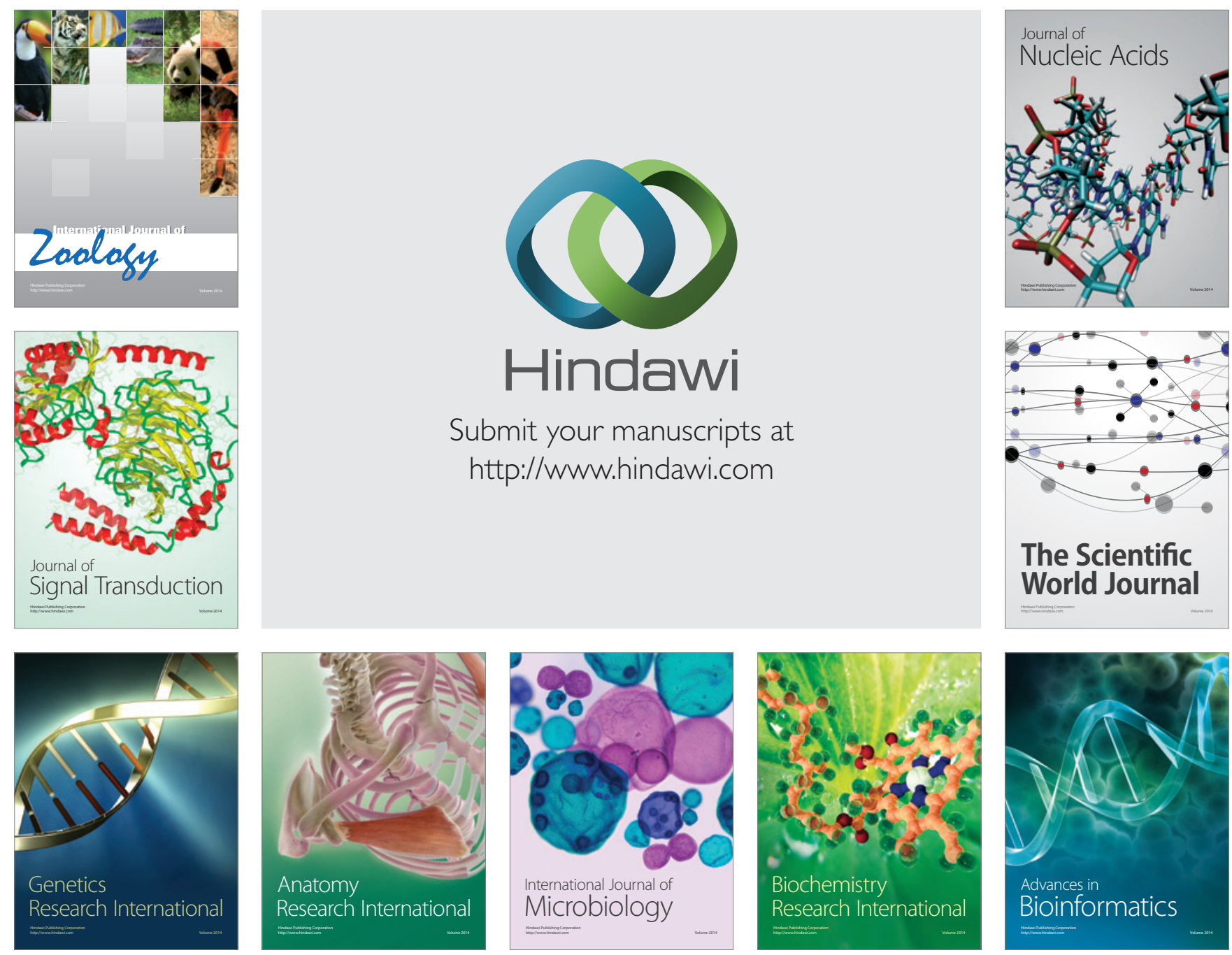

The Scientific World Journal
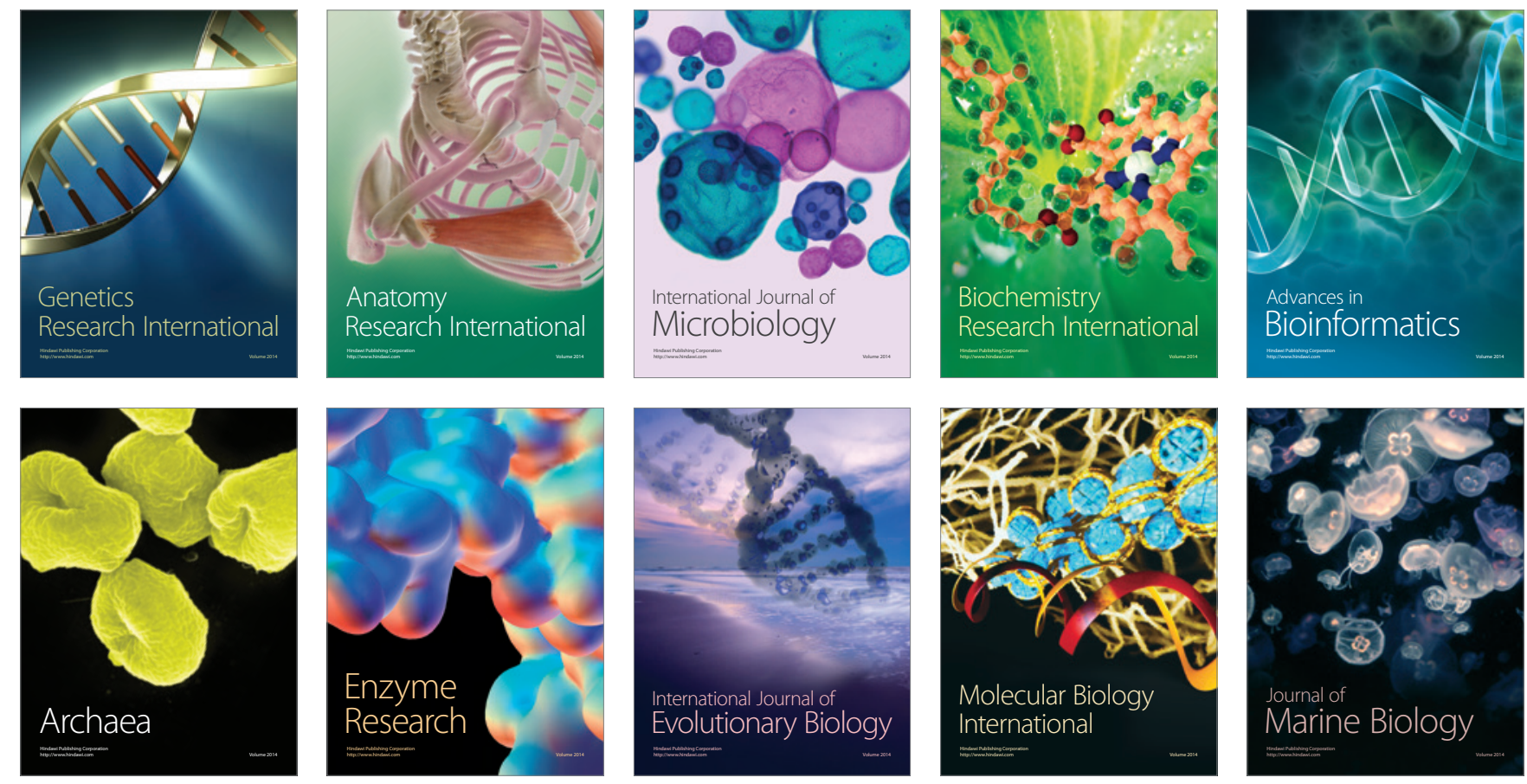